\title{
Low cost biological lung volume reduction therapy for advanced emphysema
}

\author{
This article was published in the following Dove Press journal: \\ International Journal of COPD \\ 3 August 2016 \\ Number of times this article has been viewed
}

\author{
Mostafa Bakeer' \\ Taha Taha Abdelgawad' \\ Raed El-Metwaly' \\ Ahmed El-Morsi' \\ Mohammad Khairy \\ El-Badrawy' \\ Solafa El-Sharawy ${ }^{2}$ \\ 'Chest Medicine Department, ${ }^{2}$ Clinical \\ Pathology Department, Faculty \\ of Medicine, Mansoura University, \\ Mansoura, Egypt
}

Correspondence: Mostafa Bakeer Chest Medicine Department, Faculty of Medicine, Mansoura University, Elgomhoriya St, 35516 Mansoura, Egypt Emailmbekeer10@hotmail.com
Background: Bronchoscopic lung volume reduction (BLVR), using biological agents, is one of the new alternatives to lung volume reduction surgery.

Objectives: To evaluate efficacy and safety of biological BLVR using low cost agents including autologous blood and fibrin glue.

Methods: Enrolled patients were divided into two groups: group A (seven patients) in which autologous blood was used and group B (eight patients) in which fibrin glue was used. The agents were injected through a triple lumen balloon catheter via fiberoptic bronchoscope. Changes in high resolution computerized tomography (HRCT) volumetry, pulmonary function tests, symptoms, and exercise capacity were evaluated at 12 weeks postprocedure as well as for complications.

Results: In group A, at 12 weeks postprocedure, there was significant improvement in the mean value of HRCT volumetry and residual volume/total lung capacity ( $\%$ predicted) $(P$-value: $<0.001$ and 0.038 , respectively). In group $\mathrm{B}$, there was significant improvement in the mean value of HRCT volumetry and (residual volume/total lung capacity \% predicted) ( $P$-value: 0.005 and 0.004 , respectively). All patients tolerated the procedure with no mortality.

Conclusion: BLVR using autologous blood and locally prepared fibrin glue is a promising method for therapy of advanced emphysema in term of efficacy, safety as well as cost effectiveness.

Keywords: BLVR, bronchoscopy, COPD, interventional pulmonology

\section{Introduction}

Emphysema is a chronic and progressive disease, characterized by abnormal permanent enlargement of air spaces distal to the terminal bronchioles. Because the principal defect in emphysema is hyperinflation due to destruction of elastic tissue, conventional medical treatment still remains to be symptomatic treatment and of limited value due to failure to improve elastic recoil of lung tissue. ${ }^{1}$

Surgical treatment for emphysema, involves major thoracic surgery in a generally elderly population with limited breathing capacities. It directly addresses the problem of lung hyperinflation through resection of damaged tissue. ${ }^{2}$

Therefore the clinical utility of bronchoscopic methods for achieving lung volume reduction have been evaluated in patients with advanced emphysema because those procedures are uniformly safer than surgical volume reduction. ${ }^{3}$

Biological lung volume reduction (BioLVR) is a novel endobronchial approach, which uses biological agents aiming to reduce lung volume by blocking off the most emphysematous areas with a rapidly polymerizing sealant. The mechanism of action involves resorption atelectasis from airway occlusion, subsequent airspace inflammation, and then remodeling. This remodeling will lead to scarring that induces 
contraction of lung parenchyma and functional volume reduction can be expected within 6-8 weeks. ${ }^{4}$

\section{Aim of the work}

The aim of this study was to evaluate the potential efficacy and safety of bronchoscopic BioLVR therapy in patients with pulmonary emphysema.

\section{Patients and methods}

This study was carried out at chest medicine department in collaboration with clinical pathology department and radiology department, Mansoura University Hospitals, Mansoura, Egypt from May 2013 to August 2015.

Fifteen male patients with heterogeneous emphysema were recruited in this study. The study was approved by The Medical Research Ethics Committee, Mansoura University (ID number: MD68) and all patients provided written informed consent prior to participation.

\section{Study population}

All study participants had severe airflow obstruction, heterogeneous emphysema, and respiratory symptoms despite medical therapy, and were either not eligible for, or had refused, surgical lung volume reduction. Specific study inclusion/exclusion criteria are similar to those used for previous studies of BioLVR as follows:

\section{Inclusion criteria}

1. Heterogeneous emphysema as determined by high resolution computerized tomography (HRCT) of the chest with area of destruction $\leq-950$ Hounsfield units (HU) plus:

(a) Dyspnea score of $>2$ according to Modified Medical Research Council dyspnea (mMRC) despite medical therapy.

(b) Forced expiratory volume in 1 second to forced vital capacity ratio $\left(\mathrm{FEV}_{1} / \mathrm{FVC}\right)<70 \%$ and $\mathrm{FEV}_{1}$ of $20 \%-50 \%$ of the predicted.

(c) Hyperinflation; total lung capacity (TLC) $\geq 110 \%$ predicted and residual volume/TLC (RV/TLC) $\geq 120 \%$ predicted.

2. Patients not candidate for or had refused lung volume reduction surgery.

3. Age $>40$ years.

\section{Exclusion criteria}

1. $\mathrm{FEV}_{1}<20 \%$.

2. Diffusion capacity of lung to carbon monoxide $<20 \%$.

3. Current smoker.

4. Patients not candidate for bronchoscopy.

\section{Study design}

The study is a nonrandomized, open label (quasiexperimental) safety and efficacy clinical trial, with ClinicalTrials.gov Identifier: NCT02107209.

Enrolled patients were divided into two groups:

- Group A, which included seven patients in whom autologous blood was used.

- Group B, which included eight patients in whom locally prepared fibrin glue was used.

- The selected patients were subjected to the following basic evaluation: history taking, physical examination, chest X-ray, electrocardiogragraphy, complete blood count, prothrombin time, partial thromboplastin time, international normalized ratio, arterial blood gases, liver and kidney function tests.

- The following evaluating parameters were done on admission as a basic value, then at 12 weeks postprocedure: multidetector CT chest (for HRCT volumetry), pulmonary function tests (spirometry; $\mathrm{FEV}_{1}, \mathrm{FVC}, \mathrm{FEV}_{1} /$ FVC, and lung volumes; RV, TLC, RV/TLC using single breath helium dilution method), 6-minute walk distance (6MWD), mMRC dyspnea scale, and St George's Respiratory Questionnaire (SGRQ) total score (using the revised original Arabic version) for quality of life assessment.

- HRCT volumetry; chest multidetector CT scan was done using 128 multidetector CT scanner (Philips Ingenuity Core128 scanner, Philips Medical Systems, Best, the Netherlands) and included both helical CT and HRCT. Heterogeneity was determined by computeraided diagnosis-automated HRCT. The pixel index was defined in this study as the relative area of the CT image occupied by pixels between $-1,024$ and $-950 \mathrm{HU}$. This level was chosen because it correlated best to the emphysematous changes in the lungs. ${ }^{5}$ HRCT volumetry of the most affected emphysematous part was done by quantitative densitometry, computer multiplane reconstructions of the CTs into sagittal and coronal planes plus three-dimensional rendering. ${ }^{6}$

\section{Procedure}

Bronchoscopy was done using PENTAX FB-15V fiberoptic bronchoscope (PENTAX Europe GmbH, Hamburg, Germany) under conscious sedation with 2-5 mg midazolam and topical anesthesia with 3-5 puffs of lidocaine spray $10 \%$. Supplemental oxygen was given using nasal catheter and oxygen saturation was monitored throughout the procedure.

Through the oral route, the bronchoscope was introduced and advanced to the targeted segmental bronchus that was previously determined by HRCT chest. 
In this study, we introduced a novel technique to deliver the biological agent (locally prepared fibrin glue and autologous blood) to the targeted segment using a triple lumen balloon catheter (TXR-12-A, 7 FR/200 cm, Cook Medical, Bloomington, IN, USA) (Figure 1), which was introduced through the working channel of the bronchoscope and advanced 1-2 $\mathrm{cm}$ beyond the tip of the bronchoscope. ${ }^{7}$ The triple lumen balloon catheter has three ports, one for inflation of the balloon by special air syringe (this will occlude the targeted segmental bronchus preventing regurgitation and spillover of the injected agent into other nontargeted segments) and two ports leading to separate channels throughout the catheter (Figure 2).

In group (A), autologous blood was used. A $30 \mathrm{~mL}$ blood sample was drawn from the patient (through a catheter fixed in the femoral vein) and immediately injected through one port of the triple lumen catheter, plus $3 \mathrm{~mL}$ Cyklokapron (tranexamic acid $100 \mathrm{mg} / \mathrm{mL}$ ) and $3 \mathrm{~mL}$ calcium chloride $10 \%$ (2.04 mmol of calcium) injected through the other port of the triple lumen catheter. Cyclokapron is a potent antifibrinolytic and thus could accelerate the clotting time. Calcium can decrease time required for formation of visible blood clot. Injection through both ports was done simultaneously. Mixing of the blood with cyclokapron and calcium chloride occurred distal to the inflated balloon and blood clotting occurred in the targeted segment.

After injection, the catheter was kept in position for (4-8) minutes, the specific duration was previously determined according to the clotting time of each patient. The balloon was then deflated and the catheter was withdrawn. The procedure was repeated to the next targeted segment.

In group (B), fibrin glue was used. Fibrin glue was locally prepared from plasma containing fibrinogen and thrombin. Plasma containing fibrinogen was previously prepared by

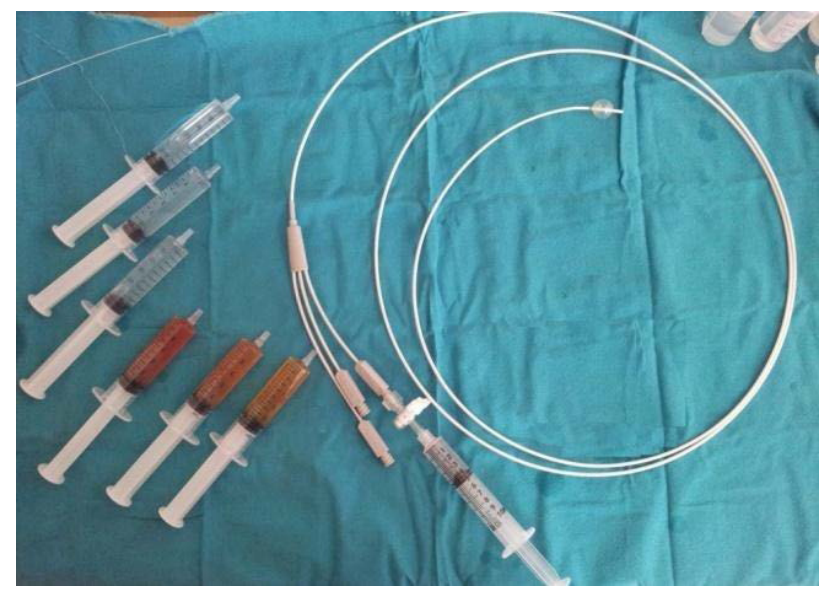

Figure I Triple lumen balloon catheter and components of locally prepared fibrin glue.
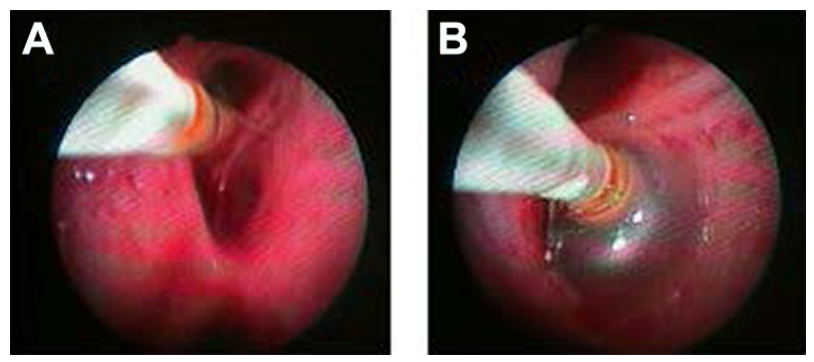

Figure 2 (A) Triple lumen balloon catheter inserted into the targeted segment. (B) Inflated balloon prevent regurgitation of the injected materials.

obtaining blood sample from the patient that underwent centrifugation after adding citrate, and then the supernatant plasma was separated. This maneuver was done in the clinical pathology department under sterile conditions. Thrombin was prepared from the commercially available Multifibrin-U, SIEMENS (Siemens Healthcare Diagnostics Products Gmbh, Marburg, Germany), bovine thrombin $(50 \mathrm{IU} / \mathrm{mL}) .{ }^{8}$ The required dosage ratio of plasma to thrombin to form a coagulum were previously calculated in the clinical pathology department after several trials. In this study, a dose of $30 \mathrm{~mL}$ fibrin glue (15 mL plasma plus $15 \mathrm{~mL}$ thrombin) was used per segment.

Patient's plasma and thrombin was injected simultaneously into the targeted segment through two separate channels of the triple lumen catheter after balloon inflation. The catheter was kept in position for 1 minute as fibrin glue formation in the targeted segment takes $<1$ minute. The procedure was then repeated in the next targeted segment.

\section{Postprocedure follow-up for early and late complications}

All patients were monitored for 24 hours postprocedure for the development of any early complications (eg, chronic obstructive pulmonary disease [COPD] exacerbations, pneumothorax, pulmonary embolism, cardiac ischemia, or myocardial infarction) as well as for late complications (eg, lung abscess and empyema).

\section{Outcomes evaluation}

(A) Primary endpoint

Reduction in the volume of the targeted emphysematous part at 12 weeks postprocedure was evaluated by:

1. Three-dimensional volumetric HRCT.

2. Reduction in (RV/TLC \% predicted) from baseline.

(B) Secondary endpoint

1. Changes from baseline at 12 weeks in $\mathrm{mMRC}$ score, SGRQ, 6MWD, postbronchodilator $\left(\mathrm{FEV}_{1} \%\right.$ predicted), and $\mathrm{FEV}_{1} / \mathrm{FVC}$ ratio.

2. Safety: presence or absence of complications. 


\section{Results}

\section{Matching criteria}

Patients' characteristics and baseline values are shown in Table 1.

There was no significant difference as regard to age between groups A and B. The baseline values were well matched with no significant difference for any variable between the two groups.

\section{Efficacy results}

A) Primary outcome: changes in HRCT volumetry and RV/ TLC (\% predicted) are shown in Table 2.

There was a statistically significant reduction in HRCT volumetry in groups A and B compared to baseline values ( $P=<0.001$ and $P=0.005$, respectively). There was no significant difference in the improvement of HRCT volumetry between groups $\mathrm{A}$ and $\mathrm{B}(P=0.726)$. $\mathrm{CT}$ images from selected patients are shown in Figures 3 and 4. Also, there was statistically significant reduction in RV/TLC in groups $\mathrm{A}$ and $\mathrm{B}$ compared to baseline values ( $P=0.038$ and $P=0.004$, respectively). There was more significant improvement in RV/TLC in the fibrin glue group than in the autologous blood group $(P=0.018)$.

B) Secondary outcomes: changes in the mMRC dyspnea scale, SGRQ score, 6MWD, and spirometric parameters are shown in Table 3.

Within both groups, there was statistically significant improvement in all secondary measures outcomes at 12 weeks postprocedure compared to baseline value. There was no

Table I Age and baseline values in both groups

\begin{tabular}{|c|c|c|c|}
\hline & $\begin{array}{l}\text { Group A } \\
(n=7)\end{array}$ & $\begin{array}{l}\text { Group B } \\
(n=8)\end{array}$ & $P$-value \\
\hline Age (years) (mean $\pm S D)$ & $55.71 \pm 4.03$ & $56.50 \pm 12.08$ & 0.873 \\
\hline \multicolumn{4}{|l|}{ COPD group (N [\%]) } \\
\hline GOLD III & I (I4.3\%) & $4(50 \%)$ & 0.143 \\
\hline GOLD IV & $6(85.7 \%)$ & $4(50 \%)$ & \\
\hline $\begin{array}{l}\text { HRCT volumetry }(\mathrm{mL}) \\
(\text { mean } \pm \mathrm{SD})\end{array}$ & $\mathrm{I}, 643.7 \mathrm{I} \pm 94.19$ & I,479.38 \pm 799.0 | & 0.581 \\
\hline $\begin{array}{l}\text { RV/TLC }(\% \text { predicted }) \\
(\text { mean } \pm \text { SD) }\end{array}$ & $154 \pm 23$ & $138 \pm 18$ & 0.152 \\
\hline mMRC $($ mean $\pm S D)$ & $3.29 \pm 0.49$ & $3.38 \pm 0.52$ & 0.738 \\
\hline SGRQ (mean \pm SD) & $65.68 \pm 12.48$ & $68.14 \pm 18.47$ & $0.77 I$ \\
\hline 6MWD $($ mean $\pm S D)$ & $315.86 \pm 52.22$ & $352.13 \pm 74.16$ & 0.300 \\
\hline $\begin{array}{l}\mathrm{FEV}_{1}(\% \text { predicted }) \\
(\text { mean } \pm \mathrm{SD})\end{array}$ & $26 \pm 4$ & $35 \pm 12$ & 0.070 \\
\hline $\mathrm{FEV}_{1} / \mathrm{FVC} \%($ mean $\pm \mathrm{SD})$ & $50 \pm 8$ & $52 \pm 18$ & 0.746 \\
\hline $\begin{array}{l}\text { RV }(\% \text { predicted }) \\
(\text { mean } \pm \text { SD) }\end{array}$ & $122 \pm 12$ & $115 \pm 4$ & 0.157 \\
\hline
\end{tabular}

Abbreviations: COPD, chronic obstructive pulmonary disease; $\mathrm{FEV}_{1}$, forced expiratory volume in I second; FVC, forced vital capacity; HRCT, high resolution computerized tomography; mMRC, modified Medical Research Council; 6MWD, 6-minute walk distance; RV/TLC, residual volume/total lung capacity; SD, standard deviation; GOLD, Global Initiative for Chronic Obstructive Lung Disease; SGRQ, St George's Respiratory Questionnaire.
Table 2 Baseline values and changes in HRCT volumetry and RV/ TLC (\% predicted) after 12 weeks

\begin{tabular}{|c|c|c|c|c|}
\hline & Baseline & 12 weeks & Change & $P$-value* \\
\hline \multicolumn{5}{|c|}{ HRCT volumetry $(\mathrm{mL})$} \\
\hline $\begin{array}{l}\text { Group A } \\
(n=7)\end{array}$ & $|, 643.7| \pm 94.19$ & $918.67 \pm 167.22$ & $-725 \pm 230$ & $<0.001$ \\
\hline $\begin{array}{l}\text { Group B } \\
(n=8)\end{array}$ & I,479.38 \pm 799.01 & $856.77 \pm 450.19$ & $-622.6 \pm 435.4$ & 0.005 \\
\hline$P$-value** & 0.581 & 0.726 & & \\
\hline \multicolumn{5}{|c|}{ RV/TLC (\% predicted) } \\
\hline $\begin{array}{l}\text { Group A } \\
(n=7)\end{array}$ & $154 \pm 23$ & $125 \pm 20$ & $-29.14 \pm 29$ & 0.038 \\
\hline $\begin{array}{l}\text { Group B } \\
(n=8)\end{array}$ & $138 \pm 18$ & $87 \pm 32$ & $-51.12 \pm 34$ & 0.004 \\
\hline$P$-value** & 0.152 & 0.018 & & \\
\hline
\end{tabular}

Notes: $* P$-value within the group at 12 weeks in comparison to baseline. ${ }^{*} * P$-value between both groups. Data are presented as mean \pm standard deviation.

Abbreviations: HRCT, high resolution computerized tomography; RV/TLC, residual volume/total lung capacity.

significant difference in the improvement between both groups at 12 weeks postprocedure except for 6MWD, which show more statistically significant improvement in the fibrin glue group compared to the autologous blood group $(P=0.006)$.

\section{Safety results (presence or absence of complications)}

All cases tolerated the procedure with no mortality. Only one patient in group A developed pneumonia at the same side of intervention 10 days postprocedure (14.3\%), which was improved by 10 days course of antibiotic, and one patient in group B developed COPD exacerbation in the first week postprocedure $(12.5 \%)$, which was controlled by medical therapy.

\section{Discussion}

\section{Primary outcome}

In our study, the primary outcome was reduction in lung volume at 12 weeks postprocedure that was identified by reduction in HRCT volumetry and RV/TLC ratio.

To assess the volume of emphysema, we used computeraided quantitative densitometric calculation of the volume $(\mathrm{mL})$ of the targeted lobe before the procedure and 12 weeks postprocedure. We found a statistically significant reduction in HRCT volumetry within group A and group B at 12 weeks postprocedure compared to baseline values $(P=0.001$ and $P=0.005$, respectively). However, there was no significant difference between groups $\mathrm{A}$ and $\mathrm{B}(P=0.726)$, as reduction in lung volume was $\left(-725 \pm 230 \mathrm{~mL}^{3}\right)$ and $\left(-622.6 \pm 435.4 \mathrm{~mL}^{3}\right)$ in groups $\mathrm{A}$ and $\mathrm{B}$.

This significant radiological response was noticed in a clinical trial implemented by Criner et al, ${ }^{3}$ who studied the therapeutic dose and safety of fibrin hydrogel in 50 patients with 

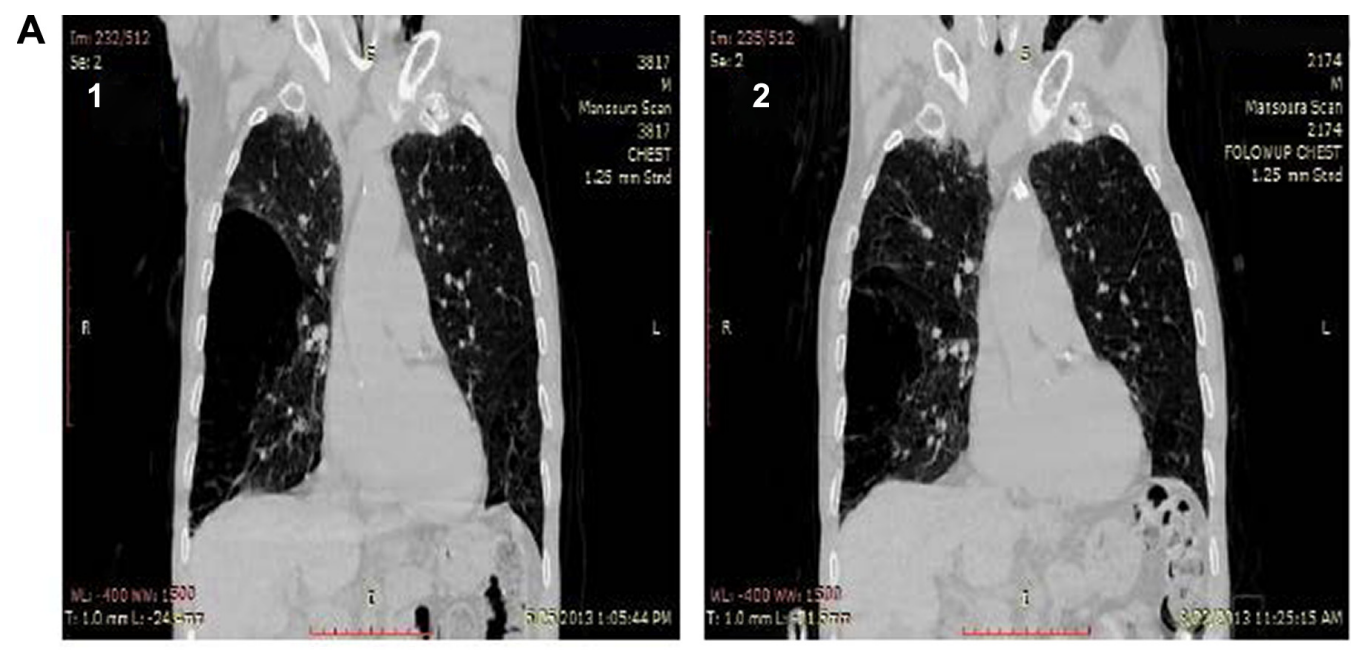

B
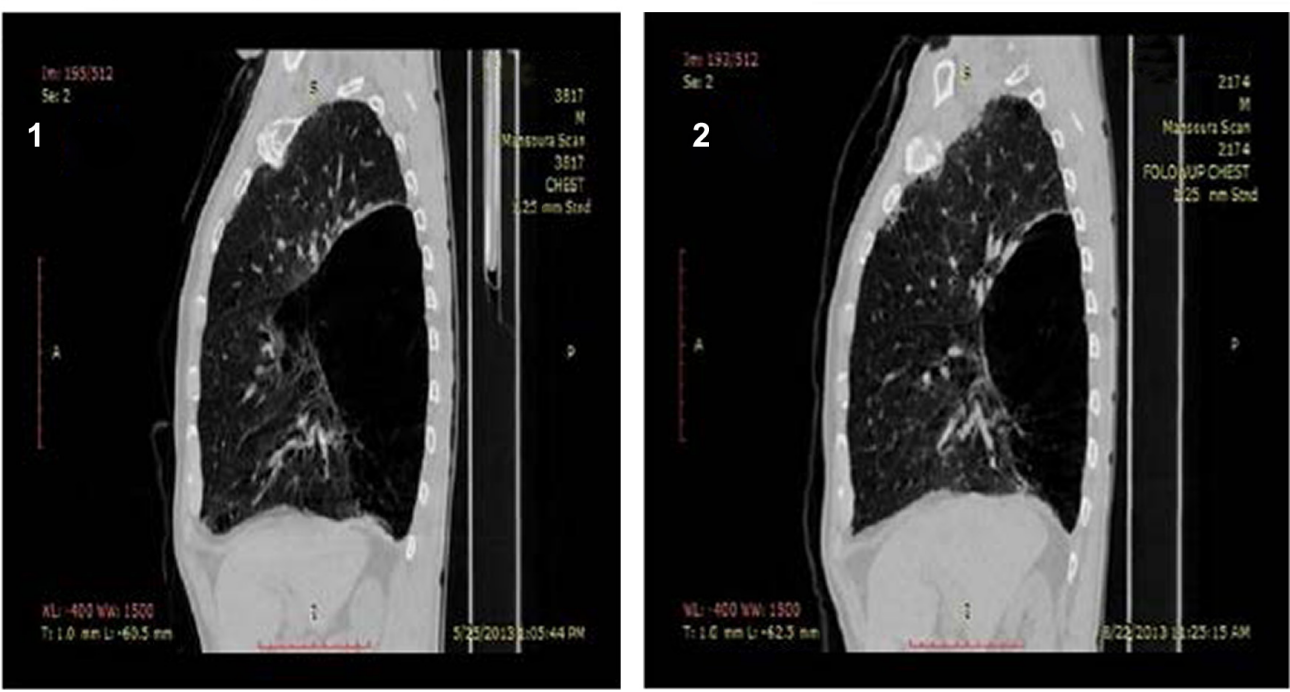

Figure 3 HRCT with coronal reconstruction $(\mathbf{A})$ and sagittal reconstruction $(\mathbf{B})$ in patient who underwent BLVR with autologous blood. Note: Reduction in emphysematous part at 12 weeks postprocedure (2) compared to baseline images (I).

Abbreviations: BLVR, bronchoscopic lung volume reduction; HRCT, high resolution computerized tomography.

advanced upper lobe emphysema, comparing high dose treatment of $20 \mathrm{~mL} /$ subsegment (in 22 patients) and low dose treatment of $10 \mathrm{~mL} /$ subsegment (in 28 patients). They showed that radiologic response (in the form of increased linear densities, scarring, and atelectasis occurred at 6 weeks) was observed at $57 \% \pm 17 \%$ of treatment sites using a dose of $10 \mathrm{~mL}$ per site and $68 \% \pm 20 \%$ using a dose of $20 \mathrm{~mL}$ per site. Radiographic responses were larger in size after high dose $(20 \mathrm{~mL} / \mathrm{subseg}$ ment) compared with low dose therapy (10 mL/subsegment).

Another clinical trial of BioLVR involved 25 patients with homogeneous emphysema was performed by Refaely et al. ${ }^{9}$ They showed that radiological response in the form of peripheral atelectasis and scarring reactions were more extensive following $20 \mathrm{~mL}$ per site treatment than $10 \mathrm{~mL}$ per site treatment.

Also, results in both groups in our study are quite close to that found by Kramer et al, ${ }^{10}$ who used AeriSeal (Aeris Therapeutics, Woburn, MA, USA) lung sealant for polymeric lung volume reduction (PLVR). They concluded that the treatment was associated with reductions in lung volume of $(-895 \pm 484 \mathrm{~mL})(P<0.001)$ in 15 patients at 12 weeks. Reductions in patients with heterogeneous upper lobe emphysema $(n=7),(-1,234 \pm 395 \mathrm{~mL})$ were significantly larger than those in patients with homogeneous emphysema $(\mathrm{n}=8),(-598 \pm 344 \mathrm{~mL}),(P=0.013)$ at 12 weeks. Herth et $\mathrm{al}^{11}$ assessed the safety and efficacy of PLVR using AeriSeal ( $20 \mathrm{~mL}$ of foam sealant) in treatment of advanced heterogeneous emphysema and found similar results as regard to radiological response. They also found that reduction in lobar volume at 12 weeks' follow-up was $188 \pm 151 \mathrm{~mL} / \mathrm{site}$. In our study, the use of low cost locally prepared fibrin glue and autologous blood is much more cost-effective.

In addition, a trial performed by Mizumori et al, ${ }^{12}$ who performed bronchoscopic lung volume reduction using transbronchial infusion of autologous blood and thrombin, demonstrated shrinkage of emphysematous area based on visual assessment of chest CT images. 
A
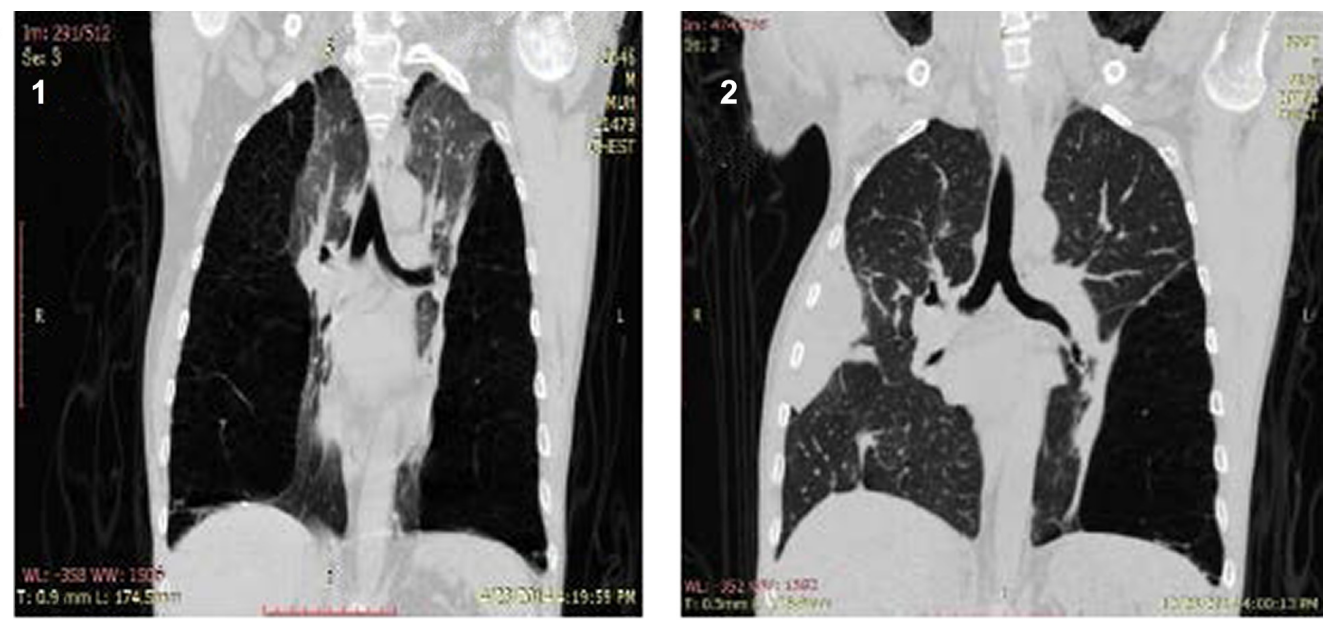

B
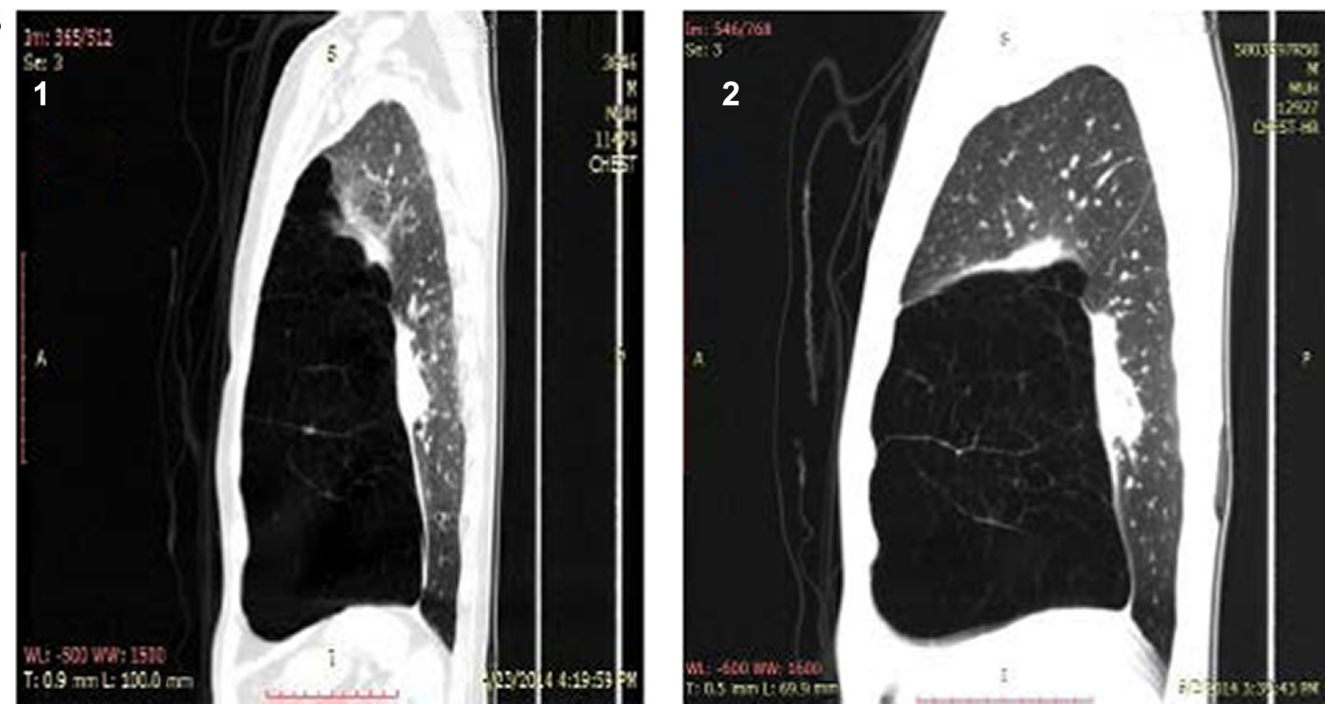

Figure 4 HRCT with coronal reconstruction (A) and sagittal reconstruction (B) in patient who underwent BLVR with fibrin glue.

Note: Reduction in emphysematous part at 12 weeks postprocedure (2) compared to baseline images (I).

Abbreviations: BLVR, bronchoscopic lung volume reduction; HRCT, high resolution computerized tomography.

In this study, there was statistically significant reduction in RV/TLC (\% predicted) in group A and group B at 12 weeks postprocedure compared to baseline values (Table 2). In addition, there was more significant improvement in RV/ TLC in the fibrin glue group than in the autologous blood group at 12 weeks postprocedure $(P=0.018)$. This might be due to more inflammatory reaction induced by fibrin glue than by autologous blood.

These results were in agreement with Criner et al, ${ }^{3}$ who noticed a statistically significant decline in RV/TLC ratio at 3 months, in both high ( $20 \mathrm{~mL} /$ subsegment $)$ and low $(10 \mathrm{~mL} /$ subsegment $)$ dosing regimens of fibrin hydrogel

Table 3 Baseline and changes in secondary outcomes measures after 12 weeks

\begin{tabular}{|c|c|c|c|c|c|c|c|}
\hline & \multicolumn{3}{|c|}{ Group A $(n=7)$} & \multicolumn{4}{|c|}{ Group B $(n=8)$} \\
\hline & Baseline & 12 weeks & $P$-value* & Baseline & 12 weeks & $P$-value* & $\boldsymbol{P}$-value** \\
\hline $\mathrm{mMRC}$ & $3.29 \pm 0.49$ & $2.00 \pm 0.00$ & $<0.001$ & $3.38 \pm 0.52$ & $2.13 \pm 0.35$ & 0.002 & 0.351 \\
\hline SGRQ & $65.68 \pm 12.48$ & $37.55 \pm 5.47$ & $<0.001$ & $68.14 \pm 18.47$ & $33.88 \pm 16.13$ & 0.001 & 0.577 \\
\hline 6MWD & $315.86 \pm 52.22$ & $331.29 \pm 52.95$ & $<0.001$ & $352.13 \pm 74.16$ & $446.63 \pm 79.56$ & 0.009 & 0.006 \\
\hline $\mathrm{FEV}_{1}$ (\% predicted) & $26 \pm 4$ & $34 \pm 5$ & 0.018 & $35 \pm 12$ & $52 \pm 25$ & 0.024 & 0.089 \\
\hline $\mathrm{FEV}_{1} / \mathrm{FVC} \%$ & $50 \pm 8$ & $66 \pm 10$ & 0.003 & $52 \pm 18$ & $65 \pm 12$ & 0.015 & 0.832 \\
\hline
\end{tabular}

Notes: $* P$-value within the group at 12 weeks in comparison to baseline. $* * P$-value between the groups at 12 weeks. Data are presented as mean \pm standard deviation. Abbreviations: FEV , forced expiratory volume in I second; FVC, forced vital capacity; mMRC, modified Medical Research Council; 6MWD, 6-minute walk distance; SGRQ, St George's Respiratory Questionnaire. 
( $P=0.028$ and $P=0.002$ for high dose group and low dose group, respectively). In addition, Refaely et $\mathrm{al}^{9}$ showed a significant reduction of hyperinflation in patients treated by BioLVR using $20 \mathrm{~mL}$ hydrogel foam per treatment site at eight subsegments.

In addition, Herth et $\mathrm{al}^{11}$ and Kramer et $\mathrm{al},{ }^{10}$ who studied the efficacy of PLVR using AeriSeal in emphysema, demonstrated improvements from baseline in RV/TLC at 12 weeks and higher dose treatment had a better response than lower dose treatment as well as more favorable results in heterogeneous than in homogeneous emphysema.

\section{Secondary outcomes}

In this study at 12 weeks postprocedure, there were statistically significant improvements in dyspnea (measured by mMRC dyspnea scale), quality of life (measured by SGRQ total score), and exercise capacity (measured by 6MWD) in both the groups. However, there was no statistically significant difference between both the groups except for $6 \mathrm{MWD}$, which was more significant in group B compared to group A $(P=0.006)$.

These results were in agreement with Kramer et al, ${ }^{10}$ who found significant improvement of mMRC dyspnea scale and SGRQ total score at 12 weeks follow-up $(P=0.011$ and $P=0.016$, respectively), while there was no significant improvement in 6MWD in the same follow-up time $(P=0.305)$.

In addition, Criner et $\mathrm{al}^{3}$ found significant improvement of mMRC dyspnea scale and SGRQ total score in the high dose group ( $20 \mathrm{~mL}$ per site treatment) at 12 weeks follow-up ( $P=0.002$ and $P=0.001$, respectively). In contrast, there was no significant improvement in 6MWD in the same follow-up time $(P=0.705)$.

With regard to spirometric measures outcomes, in this study, we found significant improvement in groups A and $\mathrm{B}$ at 12 weeks postprocedure compared to baseline values in $\mathrm{FEV}_{1} \%(P=0.018$ and $P=0.024$, respectively $)$ as well as $\mathrm{FEV}_{1} / \mathrm{FVC} \%(P=0.003$ and $P=0.015$, respectively $)$, with no statistically significant difference between the two groups.

These results were in parallel to those found by Refaely et $\mathrm{al}^{9}$ and Criner et $\mathrm{al},{ }^{3}$ where there was significant improvement in $\mathrm{FEV}_{1} \%$ in the high dose group $(20 \mathrm{~mL}$ per site treatment).

\section{Safety}

Safety was assessed in terms of the incidence of serious medical complications and adverse events potentially associated with bronchoscopic lung volume reduction therapy according to Criner et al. ${ }^{3}$
In this study, all patients tolerated the procedure without significant problems. There were no serious procedural or immediate postprocedural complications. This was in contrast to Kramer et al, ${ }^{10}$ who reported that one patient developed tension pneumothorax and was mechanically ventilated but died on day 9.

In either group, there was no spillage of the injected biological agents over pulmonary segments to the nontargeted one due to balloon inflation. This was in contrast to Herth et al, ${ }^{11}$ who reported spillage of the lung sealant (AeriSeal) from the administration site into the central airways in three patients out of 25 patients.

In this study, pneumonia occurred in one patient in group A at the same side of intervention 10 days postprocedure (14.3\%), which improved after 10 days of inpatient treatment. This ratio appears to be much higher than that found by Criner and Sternberg, ${ }^{13}$ who reported one case of pneumonia in the low dose group out of $28(3.5 \%)$ and Herth et $\mathrm{al}^{11}$ reported three cases of pneumonia out of $25(6 \%)$ as well, whereas Kramer et $\mathrm{al}^{10}$ reported two cases of pneumonia out of $20(10 \%)$. This difference may be due to the difference in number of patients as well as the use of blood as it may represent a good medium for infection.

In terms of serious medical complications, our results appear acceptable in contrast to those reported by Criner et al, ${ }^{3}$ who reported that one patient (in the low dose group) developed aspiration pneumonia after 8 hours postprocedure, followed by myocardial infarction. Another patient developed pleuritic chest pain 2 days after the procedure, and experienced myocardial ischemia. A third patient developed pneumonia 4 days after the procedure. In the high dose group, one patient developed deep venous thrombosis and pulmonary embolus 4 days postprocedure.

COPD exacerbation occurred in one patient in group B $(12.5 \%)$, which developed 1 week postprocedure and was controlled by medical therapy. This result was better than that found by Criner et al, ${ }^{3}$ who reported that COPD exacerbations within the first 6 months of treatment were observed in nine of 22 high dose patients (41\%); Refaely et $\mathrm{al}^{9}$ also reported that COPD exacerbations were observed in three of 17 patients (18\%) in the high dose group; Herth et $\mathrm{al}^{11}$ and Kramer et $\mathrm{al}^{10}$ also demonstrated that treatmentrelated COPD exacerbations were observed in eight of 25 patients $(32 \%)$ and three of 20 patients $(15 \%)$, respectively. The low incidence noted in this study could be attributed to the biological nature of agents used in addition to use of balloon catheter that prevented spill over into other nontargeted segments. 


\section{Conclusion}

BioLVR using locally prepared fibrin glue and autologous blood is a promising method for therapy of advanced heterogeneous emphysema in terms of efficacy and safety as well as cost-effectiveness.

\section{Limitations of the study}

Small number of patients recruited in the study.

\section{Acknowledgments}

Preliminary results of this study were presented at the 22nd Annual Congress of ERS, September 6-10, 2014 in Munich, Germany as thematic poster presentation. The abstract is published in the European Respiratory Journal, Vol 44 Issue Suppl 58. http://erj.ersjournals.com/ content/44/Suppl 58/P3705.

\section{Disclosure}

The authors report no conflicts of interest in this work.

\section{References}

1. Sardenberg RA, Younes RN, Deheizelin D. Lung volume reduction surgery: an overview. Rev Assoc Med Bras. 2010;56(6):719-723.

2. Gelb AF, McKenna RJ, Brenner M, Fischel R, Zamel N. Lung function after bilateral lower lobe lung volume reduction surgery for alpha1antitrypsin emphysema. Eur Respir J. 1999;14(4):928-933.
3. Criner GJ, Pinto-Plata V, Strange C, et al. Biologic lung volume reduction in advanced upper lobe emphysema: phase 2 results. Am J Respir Crit Care Med. 2009;179(9):791-798.

4. Reilly J, Washko G, Pinto-Plata V, et al. Biological lung volume reduction: a new bronchoscopic therapy for advanced emphysema. Chest. 2007;131(4):1108-1113.

5. Wang Z, Gu S, Leader JK, et al. Optimal threshold in CT quantification of emphysema. Eur Radiol. 2013;23(4):975-984.

6. Friedman PJ. Imaging studies in emphysema. Proc Am Thorac Soc. 2008;5(4):494-500.

7. Bakeer M, Abd El-Gawad T, El-Metwaly Ali R, El-Morsi A, El-Badrawy M, El-Sharawy S. Low cost biological lung volume reduction therapy for advanced Emphysema. Eur Respir J. 2014; 44(Suppl 58):P3705.

8. Dempfle CE, Keller A, Kirchner A, Heene DL. The influence of hirudin on plasma fibrinogen assays. Thromb Haemost. 1998;80(4):716-717.

9. Refaely Y, Dransfield M, Kramer MR, et al. Biologic lung volume reduction therapy for advanced homogeneous emphysema. Eur Respir J. 2010;36(1):20-27.

10. Kramer MR, Refaely Y, Maimon N, Rosengarten D, Fruchter O. Bilateral endoscopic sealant lung volume reduction therapy for advanced emphysema. Chest. 2012;142(5):1111-1117.

11. Herth FJ, Gompelmann D, Stanzel F, et al. Treatment of advanced emphysema with emphysematous lung sealant $\left(\right.$ AeriSeal $\left.^{\mathbb{}}\right)$. Respiration. 2011;82(1):36-45.

12. Mizumori Y, Mochiduki Y, Nakahara Y, et al. Effects of bronchoscopic lung volume reduction using transbronchial infusion of autologous blood and thrombin in patients with severe chronic obstructive pulmonary disease. J Thorac Dis. 2015;7(3):413-421.

13. Criner G, Sternberg AL. National Emphysema Treatment Trial: the major outcomes of lung volume reduction surgery in severe emphysema. Proc Am Thorac Soc. 2008;5(4):393-405.
International Journal of COPD

\section{Publish your work in this journal}

The International Journal of COPD is an international, peer-reviewed journal of therapeutics and pharmacology focusing on concise rapid reporting of clinical studies and reviews in COPD. Special focus is given to the pathophysiological processes underlying the disease, intervention programs, patient focused education, and self management protocols.

\section{Dovepress}

This journal is indexed on PubMed Central, MedLine and CAS. The manuscript management system is completely online and includes a very quick and fair peer-review system, which is all easy to use. Visit http://www.dovepress.com/testimonials.php to read real quotes from published authors. 